\title{
An Alternative Structure Model for the Polypentapeptide in Elastin
}

\author{
Peter C. Groß ${ }^{\mathrm{a}}$, Wulff Possart ${ }^{\mathrm{b}, *}$, and Michael Zeppezauer ${ }^{\mathrm{b}}$
}

${ }^{a}$ Fraunhofer-Institute for Manufacturing and Applied Materials Research (IFAM), Wiener Strasse 12, D-28359 Bremen, Germany

b The University of the Saarland, P.O. 151150, D-66041 Saarbrücken, Germany.

Fax: \#496813024960. E-mail: w.possart@mx.uni-saarland.de

* Author for correspondence and reprint requests

Z. Naturforsch. 58c, 873-878 (2003); received June 2/July 17, 2003

Polypentapeptides $(\mathrm{GVGVP})_{\mathrm{n}}$ which are designed in analogy to the connective tissue protein elastin are reported to transform various kinds of energy into mechanical work by the so-called $\Delta \mathrm{T}_{\mathrm{t}}$-mechanism in cross-linked macroscopic polypentapeptide (PPP) films. In the literature, the responsible element of conformation in such polypeptides is described as a $\beta$ spiral and the $\Delta \mathrm{T}_{\mathrm{t}}$ effect is explained as a sudden change of macroconformation of single polypeptide molecules from an extended but not regular state below a transition temperature $\mathrm{T}_{\mathrm{t}}$ to the $\beta$-spiral above $\mathrm{T}_{\mathrm{t}}$. We examined the secondary structure of the linear PPP $\mathrm{C}\left(\mathrm{GVGVP}_{6}\right)_{6}$ in solution with DSC, CD, UV absorption, FTIR and NMR spectroscopy. The results suggest that the $\beta$-spiral is not present in the conformational structure of the PPP molecules. The antiparallel $\beta$-sheet is proposed to be the basic regular part of conformation because it agrees with all spectroscopic data. As a consequence, the elasticity of natural elastin must be considered from a new perspective.

Key words: Peptides, Elastin, $\beta$-Spiral

\section{Introduction}

The elastic properties of natural elastin are attributed to the polypentapeptide (PPP) sequences (valine-proline-glycine-valine-glycine) (Urry, 1983). In vitro, such PPP's are reported to show a conformational transition at the temperature $T_{t}$ in aqueous solution with a simultaneous self-assembling aggregation of the peptides into ordered fibres (Urry, 1993). Moreover, the $\mathrm{T}_{\mathrm{t}}$ of the PPP's can be changed in numerous ways. This effect is called the $\Delta \mathrm{T}_{\mathrm{t}}$-mechanism and it was shown that several kinds of energy can be transformed into mechanical work by suitable $\Delta \mathrm{T}_{\mathrm{t}^{-}}$ mechanisms.

Elucidating the conformational structure of the PPP's is difficult since native elastin has limited solubility and the artificial linear PPP's show poor crystallisation. Closed cyclic peptides crystallise much better and in some cases their conformation correlates well with linear peptide chains (Urry, 1972). This approach was utilised in an X-ray diffraction study for crystals of the cyclo-pentadecapeptide cyclo-(VPGVG) 3 . As the result, a recurring $\beta$-turn was identified as the main element in the secondary structure (Cook et al., 1980). NMR experiments on the temperature dependence of the conformation lead to the conclusion that the cyclo-(VPGVG) ${ }_{3}$ and the corresponding linear PPP possess very similar conformation (Urry et al., 1989). Therefore, the conformation of cyclo$(\mathrm{VPGVG})_{3}$ was adopted to the linear form of the PPP by a mathematical procedure (Venkatachalam and Urry, 1981). In conclusion, a sequence of recurring $\beta$-turns, which Urry called the $\beta$-spiral, was deduced for the linear conformational correlate of the cyclo-(VPGVG) $)_{3}$. Finally, the $\beta$-spiral model is used to explain the $\mathrm{T}_{\mathrm{t}}$-effect and the $\Delta \mathrm{T}_{\mathrm{t}^{-}}$ mechanism. On the molecular level, a temperature rise above $T_{t}$ should result in the conformational transition where at least part of the extended random states converts into contracted $\beta$-spirals (Urry, 1993; Urry, 1995).

In this paper, the linear polypentapeptide $\mathrm{C}(\mathrm{GVGVP})_{6}(\mathrm{C}=$ cystein $)$ is studied in solution with CD, FTIR, UV and NMR spectroscopy. The thermal behaviour is analysed by DSC. According to our data, the secondary structure of this PPP deviates considerably from the picture of a $\beta$-spiral as given commonly in the literature. Instead, we conclude from our data that the antiparallel $\beta$ sheet forms the basic conformational element in our PPP. 
These results are relevant for the secondary structure of the elastin PPP's in general.

\section{Materials and Methods}

Synthesis and identification of $C(G V G V P)_{6}$

The peptide $\mathrm{C}(\mathrm{GVGVP})_{6}$ was obtained by a solid phase peptide synthesis with fmoc strategy and 2-(1H-benzotriazole-1-yl)-1,1,3,3-tetramethyluroniumhexafluorophosphate (HBTU) as activation agent (Applied Biosystems 433A automatic peptide synthesizer). The prolin-pre-loaded tritylpolystyrene resin (TCP resin) was provided by PepChem Goldammer \& Clausen (Tübingen, Germany). $\mathrm{N}$-methylpyrrolidone served as the solvent in the synthesis and piperidine was used for resin cleavage (both chemicals from Applied Biosystems, Darmstadt). Amino acids were supplied by Novabiochem (Darmstadt) in fmoc protected form including the derivative fmoc-L-Cys(Trt) for the cysteine addition step. Premature synthesis termination is avoided in the last four glycine coupling steps by using the special derivative fmoc( $\mathrm{N}^{\alpha}$-trimethoxybenzyl)-glycine (PepChem Goldammer \& Clausen, Tübingen). After cleaning with RP-HPLC, the polypeptide was identified by MALDI-TOF mass spectrometry, lyophilised and stored at $-25^{\circ} \mathrm{C}$. The mass found by mass spectrometry is $2576.9 \mathrm{~g} \cdot \mathrm{mol}^{-1}$.

\section{$D S C$}

$5.0 \mathrm{mg} \mathrm{C}(\mathrm{GVGVP})_{6}$ was dissolved in $1500 \mu \mathrm{l}$ of $100 \mathrm{~mm}$ sterilised sodium phosphate buffer. After $24 \mathrm{~h}$ dialysis (MWCO 1000, Merck tubes) with three changes of buffer, the sample was degassed and filled into the DSC pan. The differential scanning twin microcalorimeter (MicroCal VP-DSC, Northampton, USA) works with tantalum pans in the reference and sample positions (pan volume of $0.5 \mathrm{ml}$ ). Temperature scans were measured in the range of $1-110^{\circ} \mathrm{C}$ (up and down) with $\pm 1 \mathrm{~K} \cdot \mathrm{min}^{-1}$.

\section{$U V$ absorption and $C D$ spectroscopy}

The UV absorption spectra (Perkin-Elmer Lambda 9 photometer) and the CD spectra (Jasco $\mathrm{J}-715$ spectro-polarimeter) were measured in a $1 \mathrm{~mm}$ quartz cuvette (Hellma) filled with a solution of $217 \mu \mathrm{g} \cdot \mathrm{ml}^{-1} \mathrm{C}(\mathrm{GVGVP})_{6}$ in $10 \mathrm{~mm}$ phos- phate buffer at $\mathrm{pH}$ 6.9. The $\mathrm{CD}$-spectrometer was calibrated with $0.06 \%$ ammonium-d-camphor-sulfonate solution. Measurements were carried out stepwise at $20,30,40,50$ and $60{ }^{\circ} \mathrm{C}$, with $20^{\circ} \mathrm{C}$ as the starting temperature. After each heating to $60{ }^{\circ} \mathrm{C}$, the solution was cooled down to $20{ }^{\circ} \mathrm{C}$ in one step. Four temperature cycles were measured. Further CD conditions: spectral step resolution $0.5 \mathrm{~nm}$, bandwidth $0.5 \mathrm{~nm}$, sensitivity $20 \mathrm{mdeg}$, response time $0.25 \mathrm{~s}$, scan speed $50 \mathrm{~nm} \cdot \mathrm{min}^{-1}, 5 \mathrm{ac}-$ cumulations.

\section{FTIR spectroscopy}

Experiments were carried out for a peptide concentration of $15 \mathrm{mg} \cdot \mathrm{ml}^{-1}$ in $\mathrm{D}_{2} \mathrm{O}$ (Merck 99,99\%) buffered with $10 \mathrm{~mm}$ phosphate buffer at pH 6.9 and filtered. For H-D exchange, the peptide solution was heated to $60{ }^{\circ} \mathrm{C}$ for $30 \mathrm{~min}$ before measurement. The shifts of the amide I and amide II bands in the IR spectra serve for controlling the equilibrium of exchange.

All spectra were taken with a demountable liquid cell with calcium fluoride windows (LOTOriel GmbH \& Co. KG, Darmstadt, Germany) on an Excalibur FTIR spectrometer [BioRad; liquid $\mathrm{N}_{2}$ cooled MCT detector; resolution: $2 \mathrm{~cm}^{-1}$; sensitivity: 1; mirror frequency: $20 \mathrm{kHz} ; 500$ scans; Norton-Beer (medium) apodisation). The pure solvent provides the reference spectrum $\left(\mathrm{I}_{0}\right)$ for the sample spectrum (I). The transmittance spectra were calculated as $\mathrm{T}=-\left(\mathrm{I} / \mathrm{I}_{0}-1\right)$.

The interpretation of the IR transmittance spectra for the amide I region was supported by peak fitting with the software Peakfit 4.0 (Jandel Scientific; peak shape: Voigt with $50 \%$ Gauß and $50 \%$ Lorentz; other parameters: standard settings). The start values for the peak positions and for the half band width were deduced from the second derivative of the spectrum. The lowest possible number of peaks was taken in order to avoid over-interpretation. All fits resulted in a correlation coefficient $\mathrm{R}>0.999$.

\section{$N M R$}

$15 \mathrm{mg}$ of the lyophilised peptide $\mathrm{C}(\mathrm{GVGVP})_{6}$ were dissolved in $600 \mu \mathrm{l}$ of a mixture of $85 \% \mathrm{H}_{2} \mathrm{O}$ and $15 \% \mathrm{D}_{2} \mathrm{O}$ and transferred into an NMR tube (Norell 507-HP, $5 \mathrm{~mm}$ diameter). All spectra were recorded on a $500 \mathrm{MHz}$ Bruker NMR spectrome- 
ter (Karlsruhe, Germany) in the temperature range from $10-60{ }^{\circ} \mathrm{C}$. The two-dimensional experiments were done with pre-saturation of the water signals.

\section{Results and Discussion}

\section{DSC, UV absorption and CD spectroscopy}

During the first heating in DSC a strong exothermic peak with the maximum at $\sim 68^{\circ} \mathrm{C}$ is found, indicating that the peptide has stabilised. The peak is missing in the second heating curve. Hence, it is attributed to a nearly irreversible transition in the peptide solution. The peak starts at $\sim 40{ }^{\circ} \mathrm{C}$ suggesting that it represents the aggregation and the $T_{t}$-transition reported in the literature for (VPGVG) 6 in solution (Urry et al., 1985).

The kinetics and the final state of the thermally induced transitions in the aqueous $\mathrm{C}(\mathrm{GVGVP})_{6}$ solution were derived from the UV absorption spectra (190-280 nm) measured isothermally as a function of time. At $40{ }^{\circ} \mathrm{C}$ in the first heating cycle, the intensity for the peak at $190 \mathrm{~nm}$ starts to change significantly. A strong initial rise of intensity (hyperchromic effect) results in a maximum at $\sim 5$ min that is followed by a hypochromic trend. At this temperature, the DSC depicts the beginning aggregation process. However, the time dependence of the UV absorption with an increasing and a decreasing tail around the maximum indicates that two sequential processes go on at $\mathrm{T}_{\mathrm{t}}$. With the other T-steps to $50^{\circ} \mathrm{C}$ and $60^{\circ} \mathrm{C}$, the peak intensity stabilises at a plateau value. For the second heating cycle, the peak intensity at $190 \mathrm{~nm}$ increases only slightly with rising temperature. now. In conclusion, we distinguish two different transitions for the PPP in solution. A first transition starts at $\sim 40^{\circ} \mathrm{C}$ where the PPP molecules aggregate in solution. Second, the small rise of UV absorption with temperature in the aggregated solution could be caused by a conformational transition either inside the aggregates or in the remaining dissolved PPP molecules but it could also be accompanied by a temperature-induced process of aggregation and de-aggregation.

CD spectroscopy provides insight into the conformational changes in the PPP-solution during heating. In the right column of Fig. 1, the CD spectra for $\mathrm{C}(\mathrm{GVGVP})_{6}$ in phosphate buffered water are given at the various temperatures for four subsequent heating cycles. The UV absorption spectra (left column in Fig. 1) were recorded simultaneously. All CD spectra contain a minimum at $195 \mathrm{~nm}$, a maximum/shoulder at $210 \mathrm{~nm}$ and a second minimum at $220 \mathrm{~nm}$. During T-cycles $\# 1$ and \#2, both the UV and the CD spectra change irreversibly due to ongoing structuring.

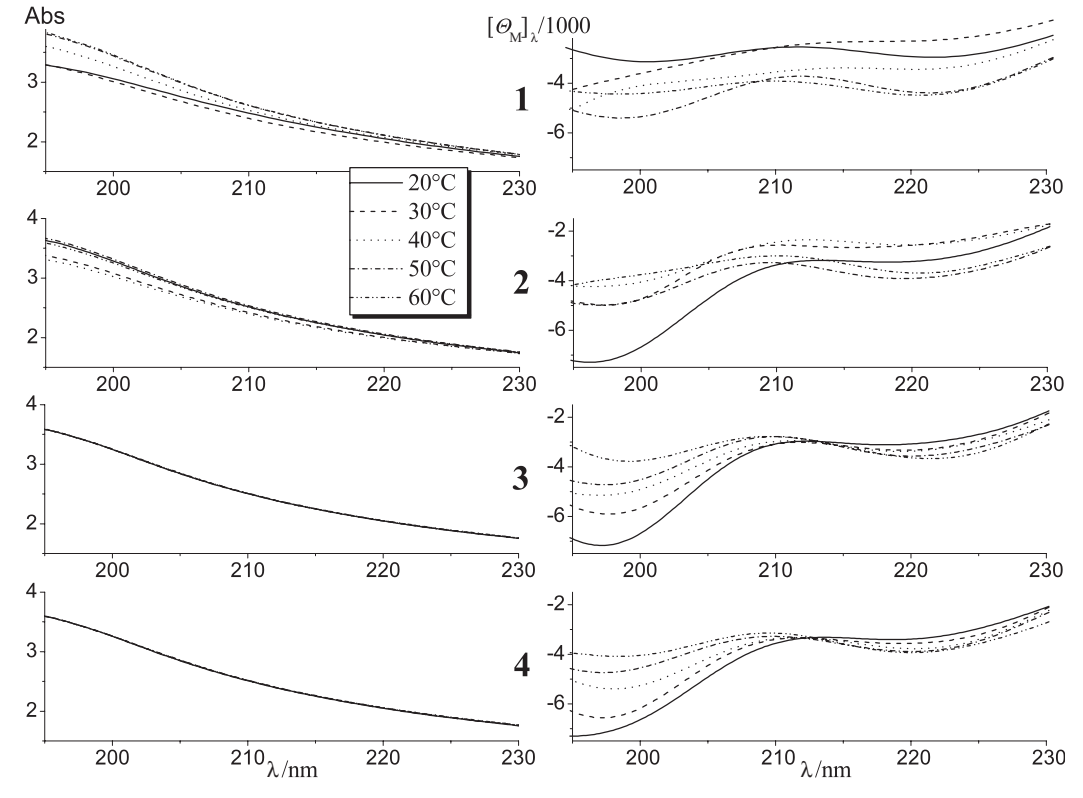

Fig. 1. CD (right column) and UV absorption (left column) spectra of $\mathrm{C}(\mathrm{GVGVP})_{6}$ in aqueous phosphate buffer for the heating cycles \#1-4 at the given temperatures. For the CD spectra, the specific molar ellipticity $\left[\Theta_{\mathrm{M}}\right]_{\lambda}$ (in ${ }^{\circ} \cdot \mathrm{cm}^{2} \cdot \mathrm{dmol}^{-1}$ ) is shown. $217 \mu \mathrm{g} \cdot \mathrm{ml}^{-1} \mathrm{C}(\mathrm{GVGVP})_{6}$ in $10 \mathrm{~mm}$ phosphate buffer, $\mathrm{pH}$ 6.9. 
From cycle \#3 on, the UV spectra do not depend on temperature anymore thus indicating that the peptide aggregation has reached equilibrium. The corresponding CD spectra show still reversible changes with temperature. This result supports the proposed conformational transition.

Basically, the shape of the CD spectra in Fig. 1 looks similar to the $\mathrm{CD}$ spectrum reported for $($ VPGVG) 200 (Urry et al., 1985). This is a first hint on the conformational similarity between our peptide $\mathrm{C}(\mathrm{GVGVP})_{6}$ and the PPP's studied by Urry.

For a more detailed discussion, a spectra analysis is executed for our CD results by the linear combination of CD spectra for reference peptides with defined secondary structure. The fit is carried out with the software PEPFIT (Reed and Reed, 1997). Table I presents the results for selected states.

At all temperatures and for all heating cycles, the analysis reveals that the mean secondary structure consists of random coil, $\beta$-turns and a remarkable part of $\beta$-sheet for our PPP in solution. The $\beta$-sheet contribution is different from a sequence of recurring $\beta$-turns in a $\beta$-spiral (Urry et al., 1985). Any fitting for our CD spectra without the $\beta$-sheet component never results in a correlation coefficient of the same quality as with the $\beta$-sheet structure. Therefore, we conclude that primary $\beta$-sheet segments determine the structure of $\mathrm{C}(\mathrm{GVGVP})_{6}$ to a considerable extent. This conclusion is confirmed by a molecular structure calculation done for our peptide with the program PHDsec (Rost and Sander, 1993). It provides a secondary structure of $94 \% \beta$-sheet for the isolated molecule $\mathrm{C}(\mathrm{GVGVP})_{6}$.

Further, the CD spectra in Fig. 1 reveal that the quite stable aggregation of molecules in solution, during the temperature cycles \#1 and \#2, are ac- companied by a considerable shift in the mean conformational composition of the PPP. According to Table I, the share fraction of all types of $\beta$ turns drops from $25 \%$ in cycle \#1 to $13 \%$ in cycle \#3. The vanished $12 \%$ of $\beta$-turns have been transformed into contents of $\beta$-sheet (growth from $30 \%$ to $36 \%$ ) and of random coil (rc; from $45 \%$ to $51 \%)$. With this, we go back to the observed maximum in $\mathrm{I}_{\mathrm{UV}}(\mathrm{t}, 190 \mathrm{~nm})$ at $40^{\circ} \mathrm{C}$ in cycle \#1. It is known that the generation of $\beta$-sheets results in a much stronger hyperchromic effect than the formation of $\beta$-turns or rc (Winter and Noll, 1998). Hence, a T-induced formation of $\beta$-sheets dominates the initial $5 \mathrm{~min}$ of agglomeration. Then, the UV intensity drops a little because part of the $\beta$ sheets transforms slowly into rc. For completed aggregation, the UV absorption at $190 \mathrm{~nm}$ is still higher and the content of $\beta$-sheet (see Table I) is larger than in the fresh PPP solution. Accordingly, the $\beta$-sheets are a preferred secondary structure for the aggregated PPP molecules.

For completed aggregation (CD in cycle \#3, Table I), heating from $20^{\circ} \mathrm{C}$ to $60{ }^{\circ} \mathrm{C}$ results in a $5 \%$ reduction of the rc content. This rc part converts mainly into $\beta$-sheets ( $4 \%$ increase) while the $\beta$ turns increase only slightly by $\sim 1 \%$. In cycle \#4, the peptide solution behaves very similarly to cycle \#3 (Fig. 1). Obviously, the conformational transition is reversible and we suppose that it is based most likely on a $\beta$-sheet - rc transition inside the PPP aggregates.

\section{FTIR spectroscopy}

Fig. 2 provides the FTIR spectra for $\mathrm{C}(\mathrm{GVGVP})_{6}$ in $\mathrm{D}_{2} \mathrm{O}$ at different temperatures with two peaks $\left(\sim 1671 \mathrm{~cm}^{-1}, \sim 1648-1652 \mathrm{~cm}^{-1}\right)$ and a shoulder $\left(1615-1621 \mathrm{~cm}^{-1}\right)$. This result agrees well with the corresponding amide I data

Table I. Secondary structure analysis of $\mathrm{C}(\mathrm{GVGVP})_{6}$ in aqueous phosphate buffer. Simulation of the experimental $\mathrm{CD}$ spectra by a linear combination of secondary structure standard curves. Values in per cent of the total area under the spectrum.

\begin{tabular}{lccccccc}
\hline Cycle & $\mathrm{T}\left[{ }^{\circ} \mathrm{C}\right]$ & $\beta$-sheet & rc & $\beta$-turn I & $\beta$-turn II & GBT & Correlation coefficient \\
\hline 1 & 20 & 30 & 45 & 5 & 10 & 10 & 0.93 \\
3 & 20 & 36 & 51 & - & - & 13 & 0.99 \\
3 & 60 & 40 & 46 & 1 & - & 13 & 0.91 \\
\hline
\end{tabular}

rc, random coil; GBT, general $\beta$-turn. 


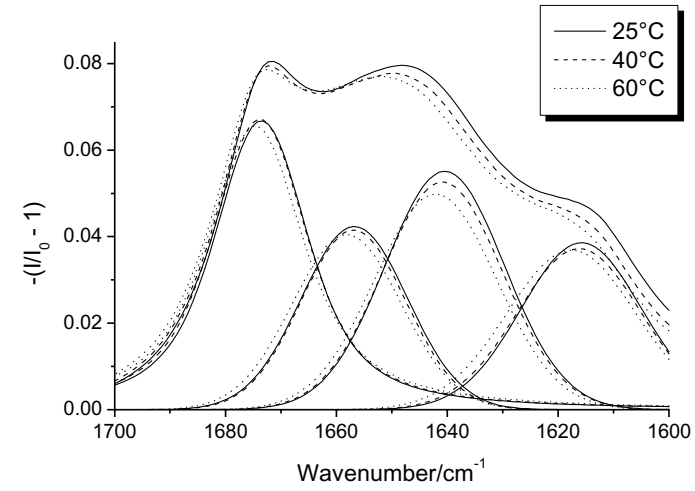

Fig. 2. Amide I spectra of $\mathrm{C}(\mathrm{GVGVP})_{6}$ in $\mathrm{D}_{2} \mathrm{O}$ at 25 , 40 and $60^{\circ} \mathrm{C}$. Each experimental curve is decomposed into 4 components. $10 \mathrm{~mm}$ phosphate buffer, $\mathrm{pH}$ 6.9; $15 \mathrm{mg} \cdot \mathrm{ml}^{-1}$; path length $5 \mu \mathrm{m}$.

in the literature (Thomas et al., 1987; Krimm and Bandekar, 1986). Hence, our linear C(GVGVP) 6 possesses a secondary structure similar to the PPP's in the literature.

The secondary structure analysis is performed by decomposing the amide I band into components which are then assigned to typical secondary structures (Singh, 2000). As shown in Fig. 2, we fit only four components since the second derivatives of our IR spectra do not justify the use of more components. The correlation coefficient is very good $(R>0.999)$. Our assignment of the four spectral components to secondary protein structures is based on a critical evaluation of the current literature (Haris, 2000). Table II provides the results. For most components, several assignments are reported. This ambiguity reflects the state of the art in interpreting peptide IR spectra. Our spectra simulation provides bands at $1673 \mathrm{~cm}^{-1}$, $1656 \mathrm{~cm}^{-1}, 1640 \mathrm{~cm}^{-1}$ and $1615 \mathrm{~cm}^{-1}$ at all tem-

Table II. Position and assignment of the conformational components of the IR spectra in Fig. 2 according to Haris (2000). The amplitude of each peak at $25^{\circ} \mathrm{C}$ is given as a relative measure with respect to peak 1 that is set to 100 .

\begin{tabular}{llll}
\hline Peak & $v_{\text {Fit }}\left[\mathrm{cm}^{-1}\right]$ & Relative $\mathrm{A}_{\mathrm{i}}$ & Assignment \\
\hline 1 & 1673 & 100 & $\beta$-aggregation, antiparallel \\
2 & 1656 & 57 & $\beta$-sheet, $\beta$-turn \\
3 & 1640 & 79 & rc \\
4 & 1615 & 57 & $\beta$-turn, $\beta$-sheet \\
\hline
\end{tabular}

rc, random coil. peratures. The peak at $1673 \mathrm{~cm}^{-1}$ is considered as a superposition of $\beta$-aggregate, regular antiparallel $\beta$-sheets and $\beta$-turns. The peak at $1656 \mathrm{~cm}^{-1}$ is quite well assigned to random coil. The band at $1640 \mathrm{~cm}^{-1}$ can be a sum of rc, $\beta$-sheet and $\beta$-turn. Here, unambiguous assignment is impossible. The simultaneous appearance of the bands at 1673 and $1615 \mathrm{~cm}^{-1}$ provides the most important conclusion. It suggests a $\beta$-aggregation of the peptide (Haris and Chapman, 1995). The backbone conformation in such aggregates is similar to $\beta$-sheets. This supports the conclusion drawn from our CD and UV absorption spectra on the partial $\beta$-aggregation during annealing.

Rising temperature causes a slight intensity decrease, mainly for the $\beta$-aggregates at $1615 \mathrm{~cm}^{-1}$, and some broadening for the peak at $1673 \mathrm{~cm}^{-1}$ (Fig. 2). This behaviour points to de-aggregation and to some increased content of $\beta$-sheet (Haris, 2000; Krimm and Bandekar, 1986) as concluded from the results of the CD spectroscopy.

\section{NMR spectroscopy}

For NMR techniques, the conformational homogeneity of the peptide in solution must be checked prior to a secondary structure analysis (Kessler, 1982). Our results, which are not presented in detail here, suggest rather a conformational heterogeneity for $\mathrm{C}(\mathrm{GVGVP})_{6}$ in aqueous medium. Accordingly, a secondary structure analysis for the PPP in aqueous solution should not be based on NMR. This is important because conformational homogeneity is assumed a priori for the PPP's in the literature (Urry et al., 1989). As a result of the observed conformational heterogeneity of the PPP's, their NOESY spectra do not provide clear evidence for the $\beta$-spiral model. Moreover, the conformational heterogeneity is in agreement with the mixture of conformations in the PPP revealed by the CD and the FTIR spectroscopies.

\section{Acknowledgements}

This research was funded by the Ministerium für Bildung, Kultur und Wissenschaft des Saarlandes. Mr. H. Nuhn measured the CD and FTIR spectra. We thank Prof. Dr. H. Welfle for the stimulating discussions about peptide spectroscopy in December 2001. 
Cook W., Einspahr H., Trapane T. L., Urry D. W., and Bugg C. (1980), Crystal structure and conformation of the cyclic trimer of a repeat pentapeptide of elastin, cyclo-(L-Valyl-L-prolylglycyl-L-valylglycyl) $)_{3}$. J. Am. Chem. Soc. 102, 5502-5505.

Haris P. I. (2000), Fourier transform infrared spectroscopic studies of peptides: Potentials and pitfalls. In: Infrared analysis of peptides and proteins 3, Am. Chem. Soc. Symp. 750, pp. 54-95.

Haris P. I. and Chapman, D. (1995), The conformational analysis of peptides using Fourier transform ir spectroscopy. Biopolymers 37, 251-263.

Kessler H. (1982), Konformation und biologische Wirkung von cyclischen Peptiden. Angew. Chem. 94, 509-520.

Krimm S. and Bandekar J. (1986), Vibrational spectroscopy and conformation of peptides, polypeptides, and proteins. Adv. Protein Chem. 38, 181-364.

Reed J. and Reed T. (1997), A set of constructed type spectra for the practical estimation of peptide secondary structure from circular dichroism. Anal. Biochem. 254, 36-40.

Rost B. and Sander C. (1993), Prediction of protein secondary structure at better than $70 \%$ accuracy. J. Mol. Biol. 232, 584-599.

Singh B. (2000), Infrared analysis of peptides and proteins: Principles and applications. Am. Chem. Soc. Symp. $\mathbf{7 5 0}$.

Thomas G. J., Prescott B., and Urry D. W. (1987), Raman amide bands of type-II b-turns in cyclo-(VPGVG) and poly-(VPGVG) $)_{9}$ and implications for protein secondary-structure analysis. Biopolymers 26, 921-936.

Urry D. W. (1972), A molecular theory of ion conducting channels: A field dependent transition between conducting and nonconducting conformations. Proc. Natl. Acad. Sci. USA 69, 1610-1614.

Urry D. W. (1983), What is elastin; what is not. Ultrastruct. Pathol. 4, 227-251.

Urry D. W. (1993), Molekulare Maschinen: Wie Bewegung und andere Funktionen lebender Organismen aus reversiblen chemischen Änderungen entstehen. Angew. Chem. 105, 859-883.

Urry D. W. (1995), Biomolekulare Maschinen aus elastischen Polymeren. Spektrum der Wissenschaft 4, $44-47$.

Urry D. W., Chang H. K., Krishna N. R., Huang D. H., Trapane T. L., and Prasad K. U. (1989), Two-dimensional proton NMR studies on poly(VPGVG) and its cyclic conformational correlate, cyclo(VPGVG $)_{3}$. Biopolymers 28, 819-833.

Urry D. W., Shaw R. G., and Prasad K. U. (1985), Polypentapeptide of elastin: temperature dependence of ellipticity and correlation with elastomeric force. Biochem. Biophys. Res. Commun. 130, 50-57.

Venkatachalam C. M. and Urry D. W. (1981), Development of a linear helical conformation from its cyclic correlate. $\beta$-spiral model of the elastin poly(pentapeptide) (VPGVG). Macromolecules 14, 1225-1229.

Winter R., and Noll F. (1998), Methoden der Biophysikalischen Chemie. Teubner, Stuttgart, 1998. 